21 Yusuf S, Peto R, Lewis J, Collins R, Sleight P. Beta blockade during and after myocardial infarction: an overview of the randomized trials. Prog Cardiovasc Dis 1985;27:335-71.

22 Rosenthal R. Meta-analytic procedures for social research. Beverly Hills: Sage, 1986.

23 DerSimonian R, Laird N. Meta-analysis in clinical trials. Controlled Clin Trials 1986;7:177-88.

24 Committee of Principal Investigators. World Health Organization cooperative trial on primary prevention of ischaemic heart disease with clofibrate to lower serum cholesterol: final mortality follow-up. Lancet 1984;ii:600-4

25 Pearce ML, Dayton S. Incidence of cancer in men on a diet high in polyunsaturated fat. Lancet 1971;i:464-7.

26 Oliver MF. Primary prevention of coronary heart disease: an appraisal of clinical trials of reducing raised plasma cholesterol. In: Yu PN, Goodwin JF, eds. Progress in cardiology. Vol 9. Philadelphia: Lea and Febiger, 1980:1-24.

27 Oliver MF. Reducing cholesterol does not reduce mortality. I Am Coll Cardiol 1988;12:814-7.

28 McCormick J, Skrabanek P. Coronary heart disease is not preventable by population interventions. Lancet 1988;ii:839-41.

Kola G. Heart panel's conclusions questioned. Science 1985;227:40-1.

30 Taylor WC, Pass TM, Shepard DS, Komaroff AL. Cholesterol reduction and life expectancy; a model incorporating multiple risk factors. Ann Int Med
ling 1987;106:605-14.

31 Isles CG, Hole DJ, Gillis CR, Hawthorne VM, Lever AF. Plasma cholesterol, coronary heart disease, and cancer in the Renfrew and Paisley survey. BrMed F 1989;298:920-4.

32 McMichael AJ, Jensen OM, Parkin DM, Zaridze DG. Dietary and endogenous cholesterol and human cancer. Epidemiol Rev 1984;6:192-216.

33 Ederer F, Leren P, Turpeinen O, Frantz ID. Cancer among men on cholesterol-lowering diets. Lancet 1971 ; ii: 203-6.

4 Roy A, Linnoila M. Suicidal behaviour, impulsiveness and serotonin. Acto Psychiatr Scand 1988;78:529-35.

35 Coccaro EF. Central serotonin and impulsive aggression. Br $\mathcal{F}$ Psychiatry 1989;155(suppl 8):52-62.

36 National Center for Health Statistics. Health United States, 1987. Washington, DC: US Government Printing Office, 1988. (DHHS publication No (PHS) DC: US Gov

37 Canner PL, Berge KG, Wenger NK, et al. Fifteen year mortality in coronary drug project patients: long-term benefit with niacin. $\mathcal{f}$ Am Coll Cardiol $1986 ; 8: 1245-55$
38 Birnbaum ZM. On the mathematics of competing risks. Washington, DC: US Government Printing Office, 1979. (DHEW publication No (PHS) 79. 1351.)

39 Kessler AR, Kessler B, Yehuda S. Changes in the cholesterol level, cholesterol-to-phospholipid mole ratio, and membrane microviscosity in rat brain induced by age and a plant oil mixture. Biochem Pharmacol 1985;34 $1120-1$.

40 Kessler AR, Kessler B, Yehuda S. In vivo modulation of brain cholesterol level and learning performance by a novel plant lipid: indications for interactions between hippocampal-cortical cholesterol and learning. Life Science 1986; 38:1185-92.

41 Coscina DV, Yehuda A, Dixon LM, Kish SJ, Leprohon-Greenwood CE. Learning is improved by a soybean oil diet in rats. Life Science 1986;38:1789.

42 Yehuda S, Leprohon-Greenwood CE, Dixon LM, Coscina DV. Effects of dietary fat on pain threshold, thermoregulation and motor activity in rats. Pharmacol Biochem Behav 1986;24:1775-7.

43 Kaplan JR, Manuck SB. The effects of fat and cholesterol on aggressive behaviour in monkeys [Abstract]. Psychosom Med 1990;52:226-7.

44 Pekkanen J, Nissinen A, Punsar S, Karvonen M. Serum cholesterol and risk of Pekkanen J, Nissinen A, Punsar S, Karvonen M. Serum cholesterol and risk of
accidental or violent death in a 25 -year follow-up. Arch Intern Med

45 Hatch FT, Reissell PK, Poon-King TMW, et al. A study of coronary heart disease in young men: characteristics and metabolic studies of patients and comparison with age-matched healthy controls. Circulation 1966;33:679. 703

46 Virkkunen M, Penttinen $H$. Serum cholesterol in aggressive conduct disorder: a preliminary study. Biol Psychiatry 1984;19:435-9.

47 Virkkunen $M$. Serum cholesterol in antisocial personality. Neuropsychobiolog 1979;5:27-30.

48 Virkkunen $M$. Serum cholesterol levels in homicidal offenders. Neuropsychobiology 1983;10:65-9.

49 Jenkins CD, Hames CG, Zyzanski SJ, et al. Psychological traits and serum lipids. I. Findings from the California psychological inventory. Psychosom Med 1969:31:115-28.

\title{
Treatment of osteoporosis with human parathyroid peptide and observations on effect of sodium fluoride
}

\author{
J Reeve, U M Davies, R Hesp, E McNally, D Katz
}

\section{Abstract \\ Objective-To evaluate the need for a randomised} study of treatment of spinal osteoporosis with human parathyroid peptide in the secondary prevention of crush fractures; to study the effect of human parathyroid hormone peptide 1-34 plus sex hormones on vertebral body cancellous bone; and, separately, to determine the effect of relatively low doses of sodium fluoride plus calcium on spinal bone mineral density.

Design-Open study of patients with primary or postmenopausal osteoporosis. All patients had serial bone densitometry of the spine by quantitative computed tomography and dual photon absorptiometry as well as serial densitometry of the radial midshaft (cortical) and radial distal (trabecular) bone by quantitative computed tomography. Changes in the spinal bone not forming the spongiosa of the vertebral bodies ("cortical" bone) were determined from the difference between the two axial measurements, after correction to the same units of measurement.

Setting-Northwick Park Hospital and Medical Research Council Clinical Research Centre.

Patients-24 Patients who fulfilled the conventional criteria for type 1 (vertebral) osteoporosis not secondary to recognised causes other than sex hormone deficiency and with at least one crush or wedge vertebral fracture and a spinal bone density (quantitative computed tomography) $<80 \mathrm{mg} / \mathrm{cm}^{3}$ or two or more fractures. Twelve patients received human parathyroid peptide and 12 sodium fluoride; they were not randomised.

Main outcome measures-Trends in axial and peripheral bone mass values determined by linear, time dependent regression analyses.
Results-The patients receiving the peptide showed a substantial increase in vertebral spongiosa (mean $25.6 \mathrm{mg} / \mathrm{cm}^{2}$ two years after the start of treatment). No significant changes were seen in spinal cortical or radial bone density. The patients receiving sodium fluoride showed roughly equal increases in cancellous and cortical bone over the same period (mean increase in vertebral spongiosa $16 \cdot 1 \mathrm{mg} / \mathrm{cm}^{3}$ ). No significant changes were seen in radial bone.

Conclusions-Treatment of postmenopausal women with human parathyroid peptide selectively increases spinal cancellous bone density by amounts that may prove useful in secondary prevention. Peptide treatment should now be tested in a randomised study in which the important end point is prevention of fractures as the usefulness of sodium fluoride in this context is doubtful.

\section{Introduction}

Three treatments have been shown substantially to increase iliac cancellous bone density in vertebral crush fracture osteoporosis: sodium fluoride (when accompanied by substantial calcium supplements ${ }^{1}$; human parathyroid peptide (fragment $1-34)^{2}$; and calcitonin alternating with oral phosphate, which is slightly less effective. ${ }^{3}$ Studies of spinal bone, however, have lagged because of the unavailability of reliable measurements of spinal bone mass. All three treatments also increased the duration of the formative phase of the iliac bone remodelling cycle so that the thickness of new bone laid down at sites of previous bone resorption was increased, ${ }^{4-6}$ and the pre-existing trabeculae became thicker. For mechanical reasons a doubling of the cross sectional area of the trabeculae may increase 
their resistance to buckling by up to fourfold ${ }^{7}$ so these studies were encouraging. It has been made technically harder to study the effects on cortical bone by histomorphometry, and no positive effects have been noted with any of these treatments. ${ }^{26}$

We studied the effects of treating osteoporosis with parathyroid peptide on the spine by using quantitative computed tomography combined with dual photon absorptiometry and on peripheral bone at two sites in the radius by using quantitative computed tomography alone. These techniques were applied serially so that changes in cortical and trabecular bone mass could be evaluated separately in both the axial and peripheral skeleton. We also studied a similar sized group of patients treated with sodium fluoride plus calcium.

We have previously observed a significant loss of peripheral cortical bone from the femoral mid-shaft in patients treated with only human parathyroid peptide $1-34 .{ }^{8}$ In this study we therefore gave the parathyroid peptide treatment together with one of two treatments that reduce cortical endosteal bone loss: oestrogen replacement therapy (accompanied when indicated by a progestogen $)^{9}$ or injections of $25 \mathrm{mg}$ nandrolone decanoate once every three weeks ${ }^{10}$ when oestrogens were contraindicated.

\section{Patients and methods}

We recruited 12 patients with two or more crush or wedge fractures of the vertebrae into an open study of treatment with parathyroid peptide (hPTH 1-34). They all had primary or postmenopausal osteoporosis as established by an absence of known causes of secondary osteoporosis on diagnostic screening, ${ }^{11}$ and were drawn from about 20 patients who were offered this treatment. Parathyroid peptide was administered by daily subcutaneous injections for one year. Nine women received oestrogen replacement therapy from the fourth month of treatment and the other patients (in whom oestrogen was contraindicated) received $25 \mathrm{mg}$ nandrolone decanoate once every three weeks. One of the patients taking nandrolone decanoate was a man; another had been treated with nandrolone for two years before starting treatment with parathyroid peptide; and the third had had a mastectomy for breast cancer 25 years previously, which subsequently showed no sign of recurrence. Compliance with oestrogen therapy was irregular in one woman; the data were analysed on an intention to treat basis. A second group of 12 women were offered treatment with sodium fluoride for osteoporosis over the same recruitment period. They included seven who for various reasons were found to be unsuitable for or did not wish to participate in the study of parathyroid peptide and two who had previously received the peptide in a cyclic regimen (on seven days each month) and in whom it had been ineffective ${ }^{11}$ (treatment had stopped 30 and 44 months before recruitment). The five others either had been unwilling to enter the trial but wished to have sodium fluoride treatment under supervised conditions or were recruited at a time when the peptide was not available. One had been taking conjugated equine oestrogens with a cyclic gestagen from one year before sodium fluoride treatment was started, and this was continued. All the patients treated with the parathyroid peptide gave informed consent as required by the hospital ethical committee. One patient taking sodium fluoride could not cooperate in the dual photon absorptiometry measurements because of severe discomfort and so was excluded from further analyses. Another patient taking sodium fluoride could not be included in the study because she had five lumbar fractures and seven thoracic vertebral fractures and no site was suitable for quantitative computed tomography.
MEASUREMENTS OF SPINAL BONE MINERAL DENSITY

Quantitative computed tomography was performed with a GE 9000 whole body scanner (IGE Medical Systems, Slough) and the technique described by Genant et al. ${ }^{12}$ Measurements of at least one lumbar vertebral body were made shortly before the start of treatment and then annually until one year after the end of treatment in patients taking the parathyroid peptide or until the end of two years' treatment in patients taking sodium fluoride, giving a total of 70 measurements in the 23 patients. Damaged vertebrae were considered unsuitable for measurement. When more than one vertebral body was measurable the results were averaged for that patient. Results were expressed in $\mathrm{mg} / \mathrm{cm}^{3}$ for cancellous (trabecular) bone plus marrow in the spongiosa of the vertebral body within a circular area exceeding $200 \mathrm{~mm}^{2}$ located anterocentrally on the cross sectional image. Water was assigned a density of zero in the analysis so that, assuming marrow to have the same density as water, the calculated density related to that of trabecular bone mineral. The radiographers were not blinded to the patients' treatments.

Integral measurements of vertebral bone density in lumbar vertebrae 2-4 were also measured with a Novo BMC Lab 22A dual photon absorptiometer (Novo Industries, Bagsvaerd, Denmark) at roughly regular intervals throughout the study. The group receiving parathyroid peptide had 132 measurements (median frequency every $3 \cdot 8$ months, range $2 \cdot 6-6 \cdot 4)$ and the sodium fluoride group 62 measurements $(6.0$ months, $4 \cdot 3-12 \cdot 0)$.

\section{PERIPHERAL BONE DENSITOMETRY}

Bone density in the radius was measured at a proximal and a distal site by an Isotom special purpose computed tomography bone densitometry system (Bioengineering Institute, University of Zurich, Switzerland). ${ }^{13}$ The proximal site was one third of the distance from the ulnar styloid to the olecranon, where only cortical bone is found. The principal measurement made at this site was the total absorption of the radial cross section ( 274 measurements), which is equivalent to measurements made with conventional non-tomographic systems. At the distal site, roughly $8 \%$ of the distance from the ulnar styloid, the radial cross section was analysed automatically so that its central $50 \%$ cross section was quantitated (258 measurements). This is an entirely cancellous (trabecular) area, and the density relates to the integral density of bone and soft tissue in the marrow space. Measurements were taken at the same time as those by vertebral dual photon absorptiometry, with additional measurements being taken between times if possible.

Care was taken to ensure that the position of the patient and regions of bone analysed on each occasion were as nearly as possible identical so as to achieve the best possible precision.

\section{BIOCHEMICAL MEASUREMENTS}

All but one of the patients receiving parathyroid peptide were admitted twice to a metabolic ward for metabolic measurements: once roughly one year before treatment and then again immediately before the end of injections with the peptide. Measurements included plasma calcium and phosphate concentrations and alkaline phosphatase activity after overnight fasting (five measurements/admission) and 24 hour urinary excretion of hydroxyproline (15 measurements/ admission).

\section{STATISTICAL ANALYSES}

The data for the two groups of patients were analysed separately. For patients receiving parathyroid peptide linear regression analysis was used to establish 
individual trends in bone density before, during, and immediately after treatment. The slopes of the regressions were allowed to change when treatment started and when it finished to allow for the changes in bone density with treatment. ${ }^{14}$ For the sodium fluoride group insufficient data were available before the start of treatment to establish trends before treatment, although all patients had had at least one measurement at each site. When the data were fitted equally successfully (that is, with similar residual mean squared deviations) by single regression slopes over the whole period of observation these were used instead. As spinal trabecular bone mineral density was measured by computed tomography less often than by absorptiometry these data were analysed by determining the differences between sequential measurements. Paired two tailed $t$ tests were used to analyse the changes in the biochemical data.

To compare the measurements made by dual photon absorptiometry with those measured by computed tomography the computed tomography data (originally expressed in $\mathrm{mg} / \mathrm{cm}^{3}$ ) were multiplied by the cross sectional area $\left(\mathrm{cm}^{2}\right)$ of trabecular bone within the cortical shell(s) of the vertebral body measured. This was approximated by determining the anteroposterior $\left(d_{1}\right)$ and lateral $\left(d_{2}\right)$ diameters of the vertebral body from the tomograms and multiplying the densities obtained by the calculated area of an ellipse $\left(\pi d_{1} \times d_{2} / 4\right)$, giving areas in most cases of about $10 \mathrm{~cm}^{2}$. The resultant quantitative computed tomography density index was then in the same dimensions $(\mathrm{g} / \mathrm{cm})$ as the measurements obtained by spinal dual photon absorptiometry. The degrees of freedom assigned reflected the numbers of subjects rather than the numbers of measurements.

The precision of measurement was estimated from the residual variance associated with the regression model adopted for the measurement site in question. For measurements made by quantitative computed tomography in the group receiving parathyroid peptide an additional measurement was made on one vertebra six months after the end of treatment for comparison with the first measurement. By fitting a linear regression through the final year's three data points an estimate of long term precision was obtained.

\section{Results}

Treatment with human parathyroid peptide (1-34) substantially increased vertebral bone mineral density. Figure 1 shows the changes in trabecular and trabecular plus cortical (integral) bone mineral density in the lumbar vertebrae. Before treatment the mean (SD) rate of change in integral bone mineral density was $-0.032(0.046) \mathrm{g} / \mathrm{cm} /$ year, equivalent to a mean rate of loss of $1.1 \%$ a year. The increase in trabecular bone density (measured by quantitative computed tomography) among patients treated with parathyroid peptide represents an increase of roughly $50 \%$ above baseline. Because the density of the soft tissue marrow is affected by its variable fat content the exact percentage above baseline cannot be determined. In most patients the marrow has a density less than that of water. The initial mean value of $47.6 \mathrm{mg} / \mathrm{cm}^{3}$ contrasts with normal values for this age group, which usually exceed $100 \mathrm{mg} / \mathrm{cm}^{3} .^{15}$ The mean increase in integral bone mineral density was similar to the increase attributable to the trabecular component and so no increase in vertebral cortical bone was documented (fig 1).

The mean change in plasma calcium concentration in patients receiving parathyroid peptide was $-0.03 \mathrm{mmol} / \mathrm{l}$ with treatment (not significant). The mean plasma phosphate concentration fell by $0.06 \mathrm{mmol} / \mathrm{l}(t=2.39, \mathrm{df}=11, \mathrm{p}<0.05)$ and the alkaline

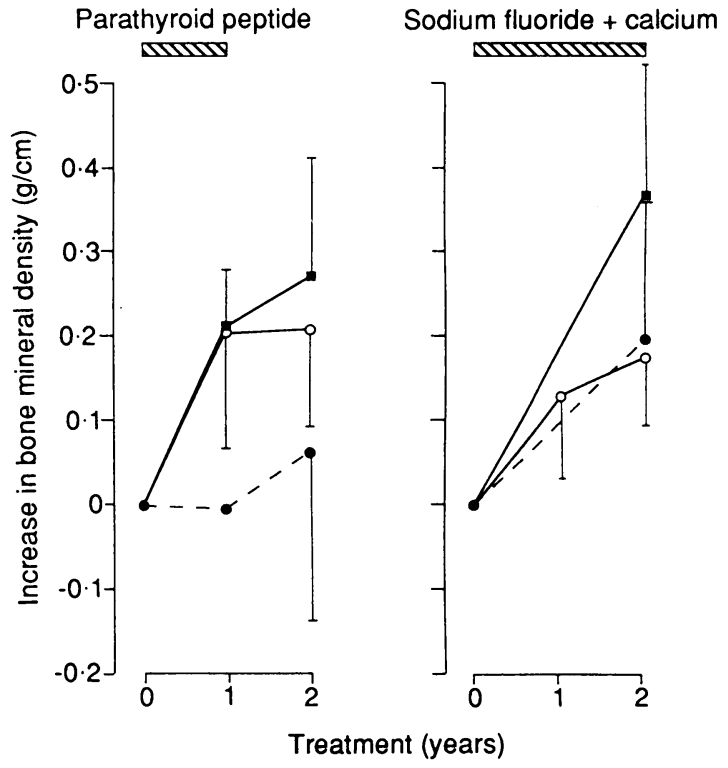

FIG 1-Mean increase in bone mineral density of lumbar spine with two treatment regimens (12 patients in group receiving parathyroid peptide and 11 in group receiving sodium fluoride). Vertical bars indicate confidence intervals. $\square=$ Measurement by dual photon absorptiometry of lumbar vertebrae 2-4, excluding only transverse processes. $O=$ Quantitative computed tomography of trabecular bone of vertebral body. $\bullet=$ Mean difference between the two gains

phosphatase activity increased by a mean of $8.4 \mathrm{U} / \mathrm{l}$, equivalent to $6 \cdot 2 \%$ of the upper limit of normal $(t=1.90, \quad 0.05<\mathrm{p}<0.10)$. Urinary excretion of hydroxyproline increased by a mean of $19 \mu \mathrm{mol} / \mathrm{day}$, which was not significant.

Treatment with sodium fluoride plus calcium resulted in substantial increases in integral bone mineral density, amounting to $13 \cdot 1 \%$ of the mean initial value over two years, but only about half the increase was attributable to improvements in trabecular bone density (fig 1). There were significant differences among patients in the size of their response to treatment as estimated by dual photon absorptiometry. When independent trends in bone density were allowed for among patients in the group treated with parathyroid peptide a substantial reduction in the residual variance associated with the regression analysis was found $(F=4.88, \mathrm{p}<0.01)$. A similar finding was observed in the group receiving sodium fluoride $(F=2 \cdot 39, \mathrm{p}<0.05)$. In contrast, no significant changes in trends of peripheral bone density among patients occurred with treatment, and no patient showed a significant loss of radial cortical or trabecular bone density with treatment. For radial cortical and
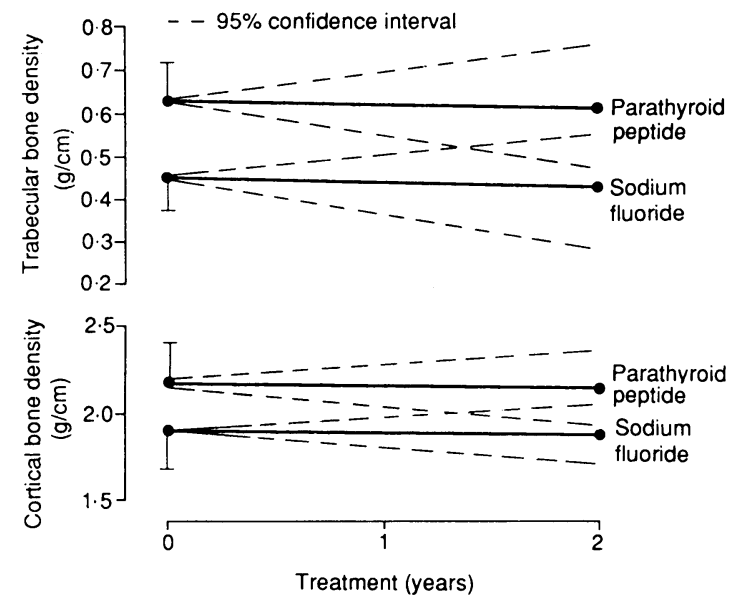

FIG 2-Mean changes in trabecular and cortical bone in radius with two treatment regimens. Vertical bars indicate 1 SE. $95 \%$ Confidence intervals (--) were derived from standard errors for individual trend lines and arbitrarily set to intersect mean trend line at time zero 
trabecular bone the data for each treatment group were therefore fitted by a single regression (fig 2). None of the four trends shown in figure 2 was significantly different from zero.

Analyses of the precision of measurement showed that dual photon absorptiometry had a precision of $4.4 \%$ and that the precision of peripheral measurements of radial cortical bone was $3 \cdot 1 \%$ and radial trabecular bone was $3 \cdot 2 \%$. Measurements obtained by quantitative computed tomography on a single vertebra were associated with an uncertainty (1 SD) of $12.6 \mathrm{mg} / \mathrm{cm}^{3}$.

\section{Discussion}

Because the patients were not treated within a randomised clinical trial the two treatment groups were not matched. Accordingly, it would be invalid to compare the efficacy of the two treatments in increasing vertebral trabecular bone density because the somewhat better response of trabecular bone among patients receiving parathyroid peptide compared with those receiving sodium fluoride could have reflected differences among the patients studied. Both sets of results, however, are relevant to the question of whether a randomised trial of parathyroid peptide plus hormone replacement therapy against only hormone replacement therapy is justified, hence their juxtaposition in this paper.

The treatment of men with osteoporosis with human parathyroid peptide 1-34 plus calcitriol ${ }^{16}$ or the peptide 1-38 in a complex cyclical regimen with calcitonin ${ }^{17}$ has been shown to increase substantially vertebral trabecular bone density. We have shown for the first time that the peptide 1-34 substantially increases trabecular bone density in the lumbar spine in the most common form of spinal or type 1 osteoporosisnamely, that occurring after the menopause with no other identifiable precipitating factor.

Previously patients treated with parathyroid peptide showed large increases in iliac trabecular bone ${ }^{2}$ that were principally attributable to the thickening of pre-existing trabeculae. ${ }^{26}$ Quantitatively, in the patients given peptide in this study the response in vertebral trabecular bone seems similar to that in iliac trabecular bone found in our earlier study. ${ }^{2}$ There were no measurable changes in cortical bone mass in the spines of these patients. This can be said confidently because the responses were similar when changes in bone mass were measured by both dual photon absorptiometry and quantitative computed tomography (fig 1). When osteoporosis was treated with only parathyroid peptide we found significant bone loss in the femoral shaft. ${ }^{8}$ This loss, if extrapolated to the skeleton as a whole, could account for a substantial part of the increments seen in iliac trabecular bone.

In contrast, in the present study no significant bone loss in cortical or trabecular bone in the radius was found with either treatment (fig 2). This suggests that both treatment regimens increased calcium absorption or retention to supply bone mineral density for the newly formed bone. With the parathyroid peptide regimen no patient's treatment was interrupted owing to untoward events or side effects. Metabolic balance and calcium absorption were studied in all but one of these patients, and in an incomplete preliminary analysis evidence was obtained that calcium balance improved sufficiently to permit conservation of cortical bone. ${ }^{18}$

In spinal osteoporosis there is a greater relative deficit of trabecular than integral spinal bone mineral because trabecular bone is lost preferentially ${ }^{15}$ and replaced by a fattier marrow. ${ }^{19}$ Human parathyroid peptide may therefore be a selective treatment for the specific defect in severe spinal osteoporosis.

In patients treated with sodium fluoride plus calcium the mean increase in bone mass in the spine of $13 \cdot 1 \%$ of the initial value over two years compares with a mean of $16.4 \%$ observed by Riggs et al with a much larger dose $^{20}$ and was double the increase observed for cancellous bone alone by quantitative computed tomography. This provides evidence that the anabolic response of spinal bone mineral to treatment with sodium fluoride necessarily affects one or more of the cortical bone of the vertebral body, the posterior arch, and the bone around the facet joints. Only one published study has analysed increases in vertebral body cancellous bone by spinal quantitative computed tomography. ${ }^{21}$ Doses in this study averaged $75 \mathrm{mg} /$ day; the mean increase in bone among female patients was $29 \mathrm{mg} / \mathrm{cm}^{3}$ over two years compared with our mean improvement of $16.1 \mathrm{mg} / \mathrm{cm}^{3}$ with half the dose of sodium fluoride.

In skeletal fluorosis due to chronic overexposure there is a sclerotic response to poisoning with fluoride, which can result in an exuberaht overgrowth of bone around the joints that articulate the spinal vertebrae as well as in thickening of end plates. ${ }^{22}$ This can lead to severe symptoms. Patients treated therapeutically with fluoride, however, have bone concentrations of fluoride lower than those seen in patients with chronic fluoride poisoning. ${ }^{22}$ Moreover, apart from trabecular coarsening in the vertebral bodies severe radiological fluorosis has rarely been reported in patients receiving sodium fluoride at this dosage. Some patients, however, do develop the lower extremity pain syndrome, which is believed to be associated with disordered repair of acquired microstructural defects ${ }^{2324}$ and with chronically excessive fluoride concentrations in the plasma. $^{23}$

Disturbingly, in two ${ }^{2025}$ of three ${ }^{26}$ recent randomised large scale studies of treatment with sodium fluoride substantial increases in axial trabecular or integral bone mineral density were obtained without any demonstrable increase in resistance to fractures after treatment compared with values in controls treated with calcium alone. Doubts must therefore continue regarding the mechanical quality of the fluoridated hydroxyapatite laid down in the newly formed bone in these patients..$^{20}$ Our data, however, suggest that half the dose used by Riggs et al may be effective in increasing spinal bone mineral, and sodium fluoride treatment should not finally be discarded until adequately tested in the dose range $30-40 \mathrm{mg} /$ day. ${ }^{27} \mathrm{It}$ is not clear at what concentrations fluoride in human bone begins to affect its mechanical properties adversely. ${ }^{28}$

For the treatment of spinal osteoporosis in which a substantial increase in cancellous bone density and strength offers the only worthwhile hope of the secondary prevention of future fractures these considerations support the view that parathyroid peptides, given either with an antiresorptive agent as in this study or with a promoter of calcium absorption, ${ }^{16}$ must now be leading candidates for treatment. They should be evaluated in randomised studies of sufficient size to determine their effect on future resistance to fracture. In the mean time their use must remain investigational.

We thank Mrs Angela Mitchell for skilled technical help and Mrs Adrien McQueen for supervising the computed tomography. Mr D Cockayne of Rorer Pharmaceuticals, Eastbourne, England, arranged the supplying and pyrogen testing of the parathyroid peptide. Ms J Pearson gave advice on regression analysis.

1 Briancon D, Meunier PJ. Treatment of osteoporosis with fluoride, calcium and vitamin D. Orthop Clin Norih Am 1981;12:629-48.

2 Reeve J, Meunier PJ, Parsons JA, et al. The anabolic effect of human parathyroid hormone fragment (hPTH 1-34) therapy on trabecular bone in involutional osteoporosis: report of a multi-centre trial. $\mathrm{Br} \mathrm{Med} \mathcal{f} 1980 ; 280$ $1340-4$ 
3 Rasmussen H, Bordier P, Marie P, et al. Effect of combined therapy with phosphate and calcitonin on bone volume in osteoporosis. Metabolic Bone Disease and Related Research 1980;2:107-11.

4 Meunier PJ, Galus K, Briancon D, et al. Treatment of primary osteoporosis with drugs that increase bone formation: sodium fluoride, hPTH 1-34, ADFR concept. In: Christiansen C, Arnaud CD, Nordin BEC, Parfitt AM Peck WA, Riggs BL, eds. Osteoporosis. Vol 2. Aalborg: Stiftsbogtrykkeri, 1984:595-602.

5 Marie PJ, Caulin F. Mechanisms underlying the effect of phosphate and calcitonin on bone histology in postmenopausal osteoporosis. Bone 1986;7:17-22.

6 Bradbeer JN, Arlot M, Reeve J, Meunier PJ. Human parathyroid peptide (hPTH 1-34) treatment increases the mean wall thickness of iliac trabecular packets of new bone in patients with crush fracture osteoporosis. Fournal of packets of new bone in patients with crush
Bone and Mineral Research 1988;3:S160.

7 Bell GH, Dunbar O, Beck JS, Gibb A. Variations in strength of vertebrae with age and their relation to osteoporosis. Calcified Tissue Research 1967;1:75-86. age and their relation to osteoporosis. Calcified Tissue Research 1967;1:75-86.
Hesp R, Hulme P, Williams D, Reeve J. The relationship between changes in femoral bone density and calcium balance in patients with involutional osteoporosis treated with human parathyroid hormone fragmen (hPTH 1-34). Metabolic Bone Disease and Related Research 1981;2:331-4.

9 Nordin BEC, Horsman A, Crilly RG, Marshall DH, Simpson M. Treatment of spinal osteoporosis in postmenopausal women. Br Med f 1980;280:451-4

10 Guesens P, Dequeker J. Long-term effect of nandrolone decanoate, l $\alpha$-hydroxyvitamin $D_{3}$ or intermittent calcium infusion therapy on bone mineral content, bone remodeling and fracture rate in symptomatic osteoporosis: a double-blind controlled study. Bone and Mineral 1986;1:347-57.

11 Reeve J, Arlot M, Price TR, et al. Periodic courses of human 1-34 parathyroid peptide alternating with calcitriol paradoxically reduce bone remodelling in spinal osteoporosis. Eur f Clin Invest 1987;17:421-8.

12 Genant HK, Cann CE, Pozzi-Mucelli RS, Kanter AS. Vertebral mineral determination by quantitative CT: clinical feasibility and normative data. 7 Comput Assist Tomogr 1983;7:554.

13 Ruegsegger P, Elsasser U, Anliker M, Guehm H, Kind H, Prader A. Quantitation of bone mineralization using computed tomography. Radiology 1976;121:93-7.

14 Draper N, Smith H. Applied regression analysis. 2nd ed. New York: Wiley, 1981:252.

15 Genant HK, Steiger P, Block JE, Glueer CC, Ettinger B, Harris ST Quantitative computed tomography: update 1987. Calcif Tiss In 1987;41:179-86.
16 Slovik DM, Rosenthal DI, Doppelt SH, et al. Restoration of spinal bone in osteoporotic men by treatment with human parathyroid hormone (1-34) and 1,25 dihydroxyvitamin D. Fournal of Bone and Mineral Research 1986;1:377-81.

7 Hesch R-D, Busch U, Prokop M, Delling G, Rittinghaus E-F. Increase of vertebral density by combination therapy with pulsatile $1-38 \mathrm{hPTH}$ and sequential addition of calcitonin nasal spray in osteoporotic patients. Calcif Tiss Int 1989;44:176-80.

18 Reeve J, Davies UM, Arlot M, et al. Parathyroid peptide (hPTH 1-34) in the treatment of osteoporosis. In: Kleerekoper M, Krane SM, eds. Clinical disorders of bone and mineral metabolism. New York: Liebert, 1989:621-8.

19 Meunier PJ, Aaron JE, Edouard C, Vignon C. Osteoporosis and the replacement of cell populations of the marrow by adipose tissue. Clin Orthop 1970;80:147-54

20 Riggs BL, Hodgson SF, O'Fallon WM, et al. Effect of fluoride treatment on the fracture rate in postmenopausal women with osteoporosis. $N$ Engl f Med 1990;322:802-9.

21 Farley SMG, Libanati CR, Mariano-Menez MR, Tudtud-Hans LA, Schulz $\mathrm{EE}$, Baylink DJ. Fluoride therapy for osteoporosis promotes a progressive increase in spinal bone density, fournal of Bone and Mineral Research $1990 ; 5:$ S37-42.

22 Boivin G, Chavassieux P, Chapuy MC, Baud CA, Meunier PJ. Skeletal fluorosis: histomorphometric analysis of bone changes and bone fluoride content in 29 patients. Bone 1989;10:89-99.

23 O'Duffy D, Wahner HW, O'Fallon WM, et al. Mechanism of acute lower extremity pain syndrome in fluoride-treated osteoporotic patients. $A m \mathcal{J}$ Med 1986;80:561-6.

24 Schnitzler CM. Stress fractures in fluoride therapy for osteoporosis. In: Christiansen C, Arnaud CD, Nordin BEC, Parfitt AM, Peck WA, Riggs BL, eds. Osteoporosis. Vol 2. Aalborg: Stiftsbogtrykkeri, 1984:629-34.

25 Kleerekoper M, Peterson E, Phillips E, Nelson D, Tilley B, Parfitt AM. Continuous sodium fluoride therapy does not reduce vertebral fracture rate in postmenopausal osteoporosis. Fournal of Bone and Mineral Research in postmenopar. $1989 ; 4:$ S376.

26 Mamelle N, Meunier PJ, Dusan R, et al. Risk-benefit ratio of sodium fluoride treatment in primary vertebral osteoporosis. Lancet 1988;ii:361-5.

27 Murray TM. A perspective on fluoride and the treatment of osteoporosis. fournal of Bone and Mineral Research 1990;5:S1-4.

28 Carter DR, Beaupre GS. Effects of fluoride treatment on bone strength. fournal of Bone and Mineral Research 1990;5:S177-84.

(Accepted 13 fune 1990)

\title{
Management of isolated thyroid swellings: a prospective six year study of fine needle aspiration cytology in diagnosis
}

\author{
Eleri L Cusick, Carol A MacIntosh, Zygmunt H Krukowski, Valerie M M Williams,
} Stanley W B Ewen, Norman A Matheson

Objective-To audit the accuracy and impact on the frequency of operation of fine needle aspiration cytology of isolated thyroid swellings.

Design-Prospective analysis over six years of cytological predictions compared with histological findings.

Setting-Thyroid clinic serving the Grampian region.

Patients-395 Consecutive patients presenting

Department of Surgery, University of Aberdeen, Aberdeen

Eleri L Cusick, FRCS,

research fellow

Carol A MacIntosh, FRCS, research fellow

Zygmunt H Krukowski, FRCS, senior lecturer

Norman A Matheson, FRCS, consultant surgeon

Department of Pathology, University of Aberdeen, Aberdeen

Valerie $M M$ Williams, $M B$, medical officer

Stanley W B Ewen,

FRCPATH, senior lecturer

Correspondence to:

Mr N A Matheson, Ward 49,

Aberdeen Royal Infirmary,

Foresterhill, Aberdeen

AB9 2ZB.

BrMed f 1990;301:318-21

Conclusions-As a basis of selection for surgical excision of isolated thyroid swellings according to prediction of neoplasia fine needle aspiration cytology is less reliable than is widely accepted. It is an adjunct to management rather than a definitive test, and negative cytological results do not exclude neoplastic disease. Further study should take

\section{Abstract}

account of the implications of repeated clinic attendances for review and aspiration as these may culminate in delayed surgical treatment.

\section{Introduction}

Most isolated thyroid swellings are benign, but it is difficult to exclude malignancy without excision and histological examination. A selective surgical policy is clearly desirable, and fine needle aspiration cytology is being increasingly used as its basis. Extensive experience in Sweden, ${ }^{1-3}$ together with work from other centres, ${ }^{14-10}$ suggests an accuracy of over $90 \%$, although some authors have been less confident. ${ }^{11} 12$

We previously reported the results of a two year prospective study of aspiration cytology in isolated thyroid swellings. ${ }^{10}$ During the first year cytological findings were concealed, and they were compared retrospectively with the histological diagnosis, which was available in $96 \%$ of cases. Sensitivity for detection of neoplasia was $86 \%$ and overall accuracy $92 \%$. During the second year cytological findings were disclosed and used to influence management. The frequency of operation decreased by $25 \%$ and the proportion of operations performed for neoplasia increased from $31 \%$ to $50 \%$. We continued this prospective evaluation to audit the accuracy and utility of aspiration cytology in our hands. swellings are with few exceptions referred to one

\section{Patients and methods}

In north east Scotland patients with thyroid 